\title{
Renewable Energy Integration: Economic Assessment of Solar Energy to Produce Biodiesel at Supercritical Conditions
}

\author{
José A. León $(D),{ }^{1,2}$ Gisela Montero ${ }^{(D)},{ }^{1}$ Marcos A. Coronado ${ }^{D},{ }^{1}$ Conrado García, ${ }^{1}$ \\ Héctor E. Campbell $\mathbb{D}^{1},{ }^{1}$ José R. Ayala $\mathbb{D}^{1},{ }^{1,2}$ Daniela Montes $\mathbb{D}^{1},{ }^{1}$ and Carlos A. Sagaste $\mathbb{D}^{1,2}$ \\ ${ }^{1}$ Instituto de Ingeniería, Universidad Autónoma de Baja California, Blvd. Benito Juárez y Calle de la Normal S/N, \\ Col. Insurgentes Este, 21280 Mexicali, BC, Mexico \\ ${ }^{2}$ Facultad de Ingeniería, Universidad Autónoma de Baja California, Campus Mexicali, Blvd. Benito Juárez y Calle de la Normal S/N, \\ Col. Insurgentes Este, 21280 Mexicali, BC, Mexico
}

Correspondence should be addressed to Gisela Montero; gmontero@uabc.edu.mx

Received 21 March 2018; Accepted 5 July 2018; Published 22 July 2018

Academic Editor: Juan M. Coronado

Copyright (C) 2018 José A. León et al. This is an open access article distributed under the Creative Commons Attribution License, which permits unrestricted use, distribution, and reproduction in any medium, provided the original work is properly cited.

In recent years, research on noncatalytic methods for biodiesel production has increased, mainly processes under supercritical conditions that allow the processing of waste vegetable oils (WVO) without the need to use catalysts, where the absence of catalyst simplifies the processes of purification of biodiesel. The high consumption of alcohol and energy to maintain the appropriate conditions of pressure and temperature of the reaction has turned the processes of supercritical conditions into an unfeasible method. However, the stages of biodiesel purification and methanol recovery are more straightforward, allowing the reduction of the total energy consumption by $25 \%$ compared to alkaline methods. Therefore, the present work describes a study through Aspen Plus ${ }^{\circledR}$ of the production of biodiesel by a process in supercritical conditions with WVO as raw material. Also, a solar collector arrangement was structured using the TRNSYS ${ }^{\circledR}$ simulator to supply energy to the process. To evaluate the economic feasibility of the proposed process, the installation of a pilot plant in Mexicali, Baja California, was considered. The internal rate of return (IRR) and the net present value (NPV) were determined for ten-year period. The planned system allows supplying solar energy, $69.5 \%$ of the energy required by the process, thus reducing the burning of fossil fuels and the operation cost. Despite the additional investment cost, for the solar collectors, the process manages to maintain a competitive production cost of USD $0.778 / 1$ of biodiesel. With an IRR of $31.7 \%$, the investment is recovered before the fifth year of operation. The integration and implementation of clean technologies are vital in the development of the biofuels.

\section{Introduction}

Increasing human demand for energy from fossil fuels has generated important environmental consequences worldwide. In several countries, programs have been implemented to mix fossil fuels with biofuels to reduce dependence on fossil fuels and to obtain environmental benefits, including mitigation of climate change. One of the most promising renewable fuels as an alternative to diesel is biodiesel, which consists of a mixture of monoalkyl esters of long-chain fatty acids derived from renewable lipids such as vegetable oils or animal fats [1].

Biodiesel is a biofuel that presents a sustainable alternative to the use of fossil fuels because it can be produced from renewable resources and its implementation in diesel engines does not require significant modifications. However, the costs of producing biofuels and energy consumption have been the primary obstacles in its industrialization and commercialization, and this has led to the investigation of various raw materials, reaction media, and designs in biodiesel production processes, seeking to increase yields and make energy consumption more efficient. All of this contributes to achieving competitive production costs and increasing the inclusion of biodiesel in the market. Using waste vegetable oils to obtain biodiesel can reduce the cost of production from $60 \%$ to $90 \%$ [2].

Waste vegetable oils (WVO) are considered the most promising source material for biodiesel production despite 


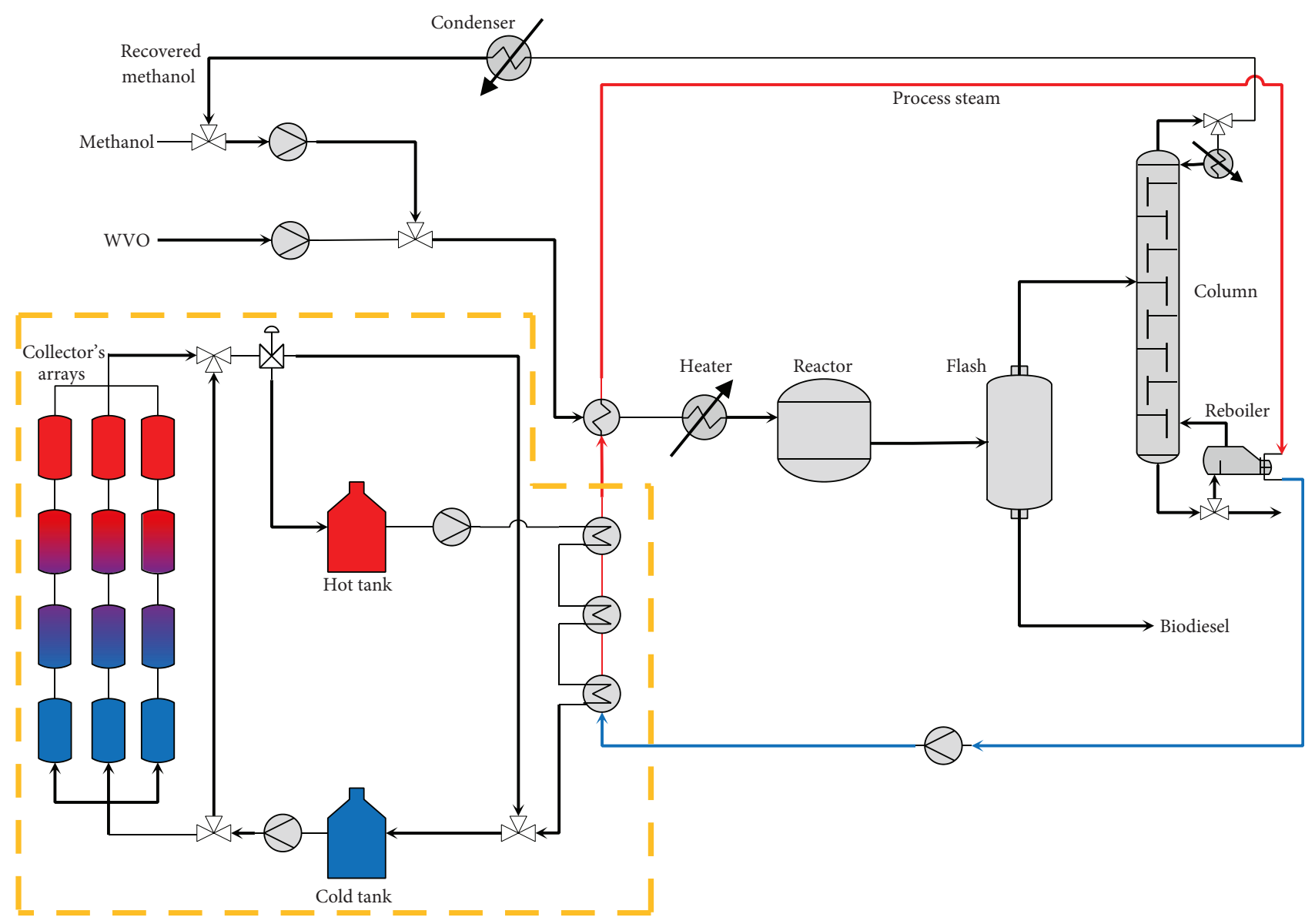

FIgURE 1: Process for the production of biodiesel in supercritical conditions powered by solar energy.

some disadvantages, such as its high free fatty acid content (FFA), which require pretreatment to be used in biodiesel produced by alkaline route. Research on noncatalytic methods for biodiesel production has recently increased, where working with WVO and the absence of catalyst simplifies the processes of biodiesel purification. One of the main noncatalytic processes studied is the supercritical condition process (SCP) [3]. The most common SCP consists of the transesterification of triglycerides contained in vegetable oils and the simultaneous esterification of FFA at pressures of 8.4 MPa to $35 \mathrm{MPa}$ and temperatures of $320^{\circ} \mathrm{C}$ to $350^{\circ} \mathrm{C}$ [4]. The high consumption of alcohol and energy to maintain the appropriate conditions of pressure and temperature in the reaction directly affects the viability of the SCP. However, the stages of biodiesel purification and recovery of methanol are more straightforward, allowing to reduce the total energy consumption by approximately $25 \%$ compared to alkaline methods [5].

Solar energy has enormous potential for exploitation due to its abundance, and its use has been increasing, for example, in domestic heating water, air conditioning, energy supply to industrial processes, and even in the electric power generation [6-8]. By harnessing the energy provided by the sun, it is possible to reduce the energy consumption of industrial processes, usually produced from fossil fuels. Due to the high energy consumption of the SCP, the implementation of solar energy as the main source of energy would imply great benefits for the process. In the present work, a series of simulations were performed that represent the process of production of biodiesel in supercritical conditions, with WVO as raw material, in which solar collectors were used in supplying energy to the process.

\section{Methodology}

The current study is focused on the production of biodiesel under supercritical conditions and the viability of solar energy as a source of thermal energy for the process. In Figure 1, the diagram that describes these processes can be seen.

In previous studies, a methodology was developed for the evaluation of the coupling of solar energy to a biodiesel production process. Where the energy loads were determined from the biodiesel production simulation in Aspen Plus, an array of solar collectors was structured through TRNSYS to supply the required energy in the recovery of methanol for the process [9]. This work starts with the previously developed methodology, but the study explores not only the application of solar energy in the recovery of solvents but also in the reaction conditions.

2.1. Raw Material. The raw material used for the production of biodiesel consists of WVO which have been widely used in 
TABLE 1: Representative composition of canola WVO.

\begin{tabular}{lc}
\hline Component & $\begin{array}{c}10 \% \text { FFA } \\
\text { Mass fraction }\end{array}$ \\
\hline Triolein & 0.720 \\
Trilinolein & 0.180 \\
Oleic acid & 0.060 \\
Linoleic acid & 0.030 \\
Linolenic acid & 0.010 \\
\hline
\end{tabular}

various studies [10-12]. Triolein has been extensively used as a representative compound of a vegetable oil and methyl oleate as the biodiesel produced from this oil. However, there are various components in vegetable oil that should be taken into account in a simulation.

Canola oil is one of the most consumed vegetable oils in Mexico [13], and it was therefore selected for this analysis. Based on data reported in the literature, the main triglycerides and FFAs that formed canola oil were determined [14]. It proposed a model of components to represent a more accurate and near to real composition of canola oil.

The percentage of FFA is used to symbolize the level of degradation of vegetable oil due to its use in cooking food. The composition of the WVO utilized in the simulation is exposed in Table 1.

2.2. Biodiesel SCP. Conventionally, the biodiesel production consists of the transesterification of triglycerides through basic or acid catalysis where glycerol is produced as a byproduct. In a biodiesel SCP, the triglycerides and FFA of oil are simultaneously transformed into biodiesel, without the need for catalysts due to the operating conditions. Recent research has indicated that it is possible to produce up to an additional $10 \%$ biofuel if the glycerol formed by the transesterification reaction is completely decomposed into 1,2,3-trimethyl glycerol triether. Thus, certain properties of biodiesel could be improved, favouring the cetane number [15]. Therefore, in this research, it was considered that all glycerol is decomposed into 1,2,3-trimethyl glycerol triether and incorporated into the biodiesel. Equations (1) and (2) indicate the reactions from which the biodiesel production was simulated. Equation (1) is the overall transesterification reaction for triglycerides while (2) is the esterification reaction for FFA. Due to the presence of FFA in the WVO, both reactions were considered simultaneously.

The production of biodiesel was simulated in Aspen Plus and was designed to process $100 \mathrm{~kg} / \mathrm{h}$ of WVO. The process consists of four main stages, which are described below.

First, the oil and methanol are brought to a pressure of 150 bar. Subsequently, its temperature is raised to $350^{\circ} \mathrm{C}$ in a series of heat exchangers. Once the appropriate pressure and temperature conditions have been reached, the reactants enter into a stoichiometric reactor. In which, five simultaneous reactions are carried out: two transesterification reactions for each of the triglycerides and three esterification reactions for the different FFAs. Both transesterification and esterification reactions have a yield of $98 \%$ and a molar ratio of methanol-triglycerides and methanol-FFA of $9: 1$.

$$
\begin{aligned}
& \mathrm{C}_{3} \mathrm{H}_{5}(\mathrm{OCOR})_{3}+6 \mathrm{CH}_{3} \mathrm{OH} \longleftrightarrow 3 \mathrm{RCOOCH}_{3} \\
& \quad+\mathrm{C}_{3} \mathrm{H}_{5}\left(\mathrm{OCH}_{3}\right)_{3}+3 \mathrm{H}_{2} \mathrm{O} \\
& \mathrm{RCOOH}+\mathrm{CH}_{3} \mathrm{OH} \longleftrightarrow \mathrm{RCOOCH}_{3}+\mathrm{H}_{2} \mathrm{O}
\end{aligned}
$$

Purification of the biodiesel is carried out in a flash separation tank, under conditions of 1 bar and $95^{\circ} \mathrm{C}$. Finally, the outlet steam enters a distillation column, where the main objective is to recover the excess of methanol. The distillation is carried out in an 8-stage column, with feed in step four and a reflux ratio of 1.5 .

In the simulation, two systems of thermodynamic properties were used, RK-Aspen for the stages that operate in supercritical conditions and UNIFAC-LL for the stages of purification of biodiesel and recovery of methanol.

2.3. Solar Thermal Energy Collection and Supply System. The supply of thermal energy through solar energy is used to maintain the temperature conditions suitable for the reaction and in the recovery of methanol. Due to the high operating temperatures required by the process, parabolic trough collectors (PTCs) were selected for the capture of solar energy. PTCs have been used extensively in the generation of electricity because they can reach temperatures above $400^{\circ} \mathrm{C}$ [16]. The capture of solar energy was simulated in TRNSYS, considering the climatic conditions for the city of Mexicali, located in the northwest region of Mexico, whose annual average solar radiation has been determined as suitable for the exploitation of solar resources [17].

The system of supply and storage of the thermal energy necessary for the continuous operation of the process is carried out through the solar heating of a heat transfer fluid (HTF). From the HTF at high temperature, it is possible to generate process steam. The HTF selected for the transport of thermal energy was thermal oil, a eutectic mixture of biphenol and diphenol oxide, the trade name of which is Therminol ${ }^{\circledR}$ VP-1 [18].

The system diagram for HTF heating and storage is exhibited in Figure 2. The energy storage system consists of a storage tank for the fluid prior to heating (tank 1) and one for the heated fluid (tank 2). The heating is effected by the arrangement of the solar collectors and a series of heat exchangers, which represent the stages of the steam generation that provide thermal energy to the biodiesel production process.

For the sizing of the array of solar collectors, the annual solar fraction was utilized, which is a commonly used parameter in the design and optimization of solar energy capture systems $[19,20]$. The solar fraction is a better indicator of the performance of a solar energy system compared to other parameters such as the efficiency of the collectors or the heat factor removed because it shows an overall performance of the system and not a single individual component [21]. The solar fraction is described as the relation between the contributions of solar energy to the total energy required by the process:

$$
f=\frac{Q_{\mathrm{s}}}{Q_{\mathrm{s}}-Q_{\text {Aux }}},
$$




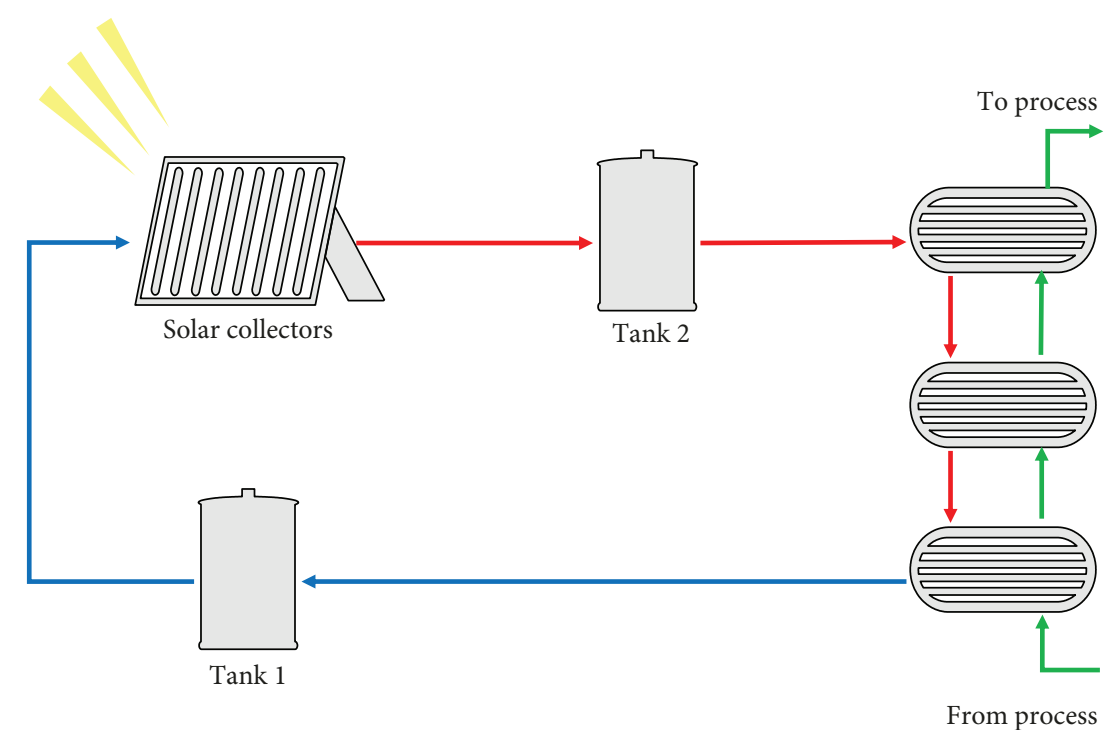

FiguRE 2: Block diagram of the solar thermal energy storage system.

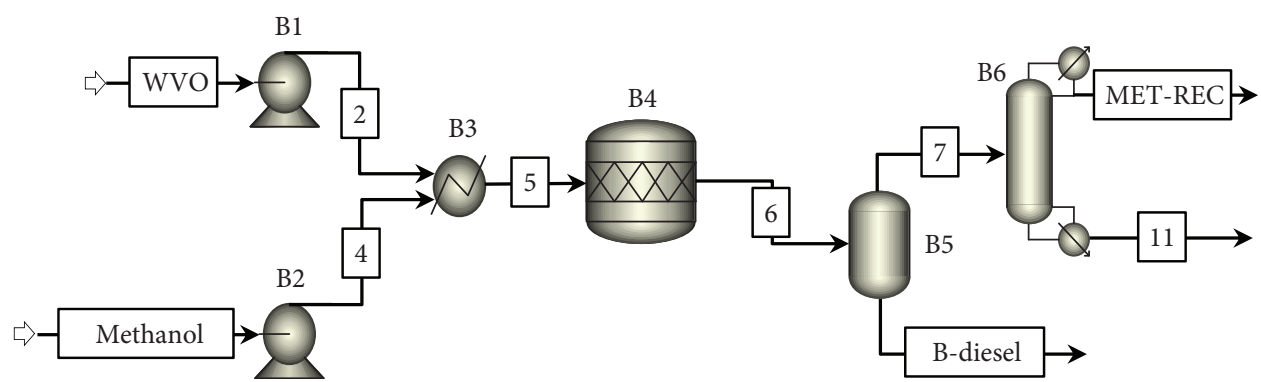

FIgUre 3: Aspen Plus diagram of the biodiesel production process at supercritical conditions.

where $f$ is the solar fraction, $Q_{\mathrm{s}}$ is the heat contributed by the solar energy to the process, and $Q_{\text {Aux }}$ is the auxiliary thermal energy required. As the solar fraction increases in a solar energy system, the amount of fossil energy used for auxiliary heating is lower [22]. The solar fraction, as a parameter, is used to analyze the variation of it with different system components, such as collection areas, various working fluids, volumes of storage tanks, and building materials. When a system is properly designed, for example, when the energy demand of the process is almost entirely covered, the addition of more collectors does not lead to an increase in the use of solar energy. In periods of high solar radiation, the system produces excess heat, which leads to not only to higher heat losses in the collectors but also to lower efficiency. Overdimensioning of solar systems involves higher costs than the benefits of energy collection. Moreover, during periods of low solar radiation, the uptake of energy is higher but the total annual energy captured is lower than in the original system [23].

\section{Results and Discussion}

Simulating biodiesel SCP was possible. In the simulation, $100 \mathrm{~kg} / \mathrm{h}$ of canola WVO is processed. The simulation diagram and streams of importance are displayed in Figure 3 and Table 2, respectively.

According to the results of the simulation, in the biodiesel SCP, a production of $107.17 \mathrm{~kg} / \mathrm{h}$ can be maintained which represents a $95.4 \%$ yield in the final biodiesel production. The B-diesel stream is composed of $97.75 \%$ biodiesel. Also, according to the information of the R-MET stream, it is possible to recover $87.6 \%$ of the unreacted methanol in stream 6 . Stream 11 is mostly composed of $42 \%$ water and $39 \%$ trimethyl triether. However, this stream is considered as waste due to the low mass flow of $12.86 \mathrm{~kg} / \mathrm{h}$ and the trimethyl triether could be purified if a large scale plant is planned. The energy demand of the process is presented in Table 3.

Through Aspen Plus, it was estimated that a flow of $220 \mathrm{~kg} / \mathrm{h}$ of thermal oil at $320^{\circ} \mathrm{C}$ is necessary to generate the process steam. Under these conditions, the HTF can only generate enough steam to supply $22.9 \mathrm{~kW}$ of the required power to the exchanger (B3), which represents $76.5 \%$ of the energy necessary by the B3 module.

Thermal energy storage and supply system were structured through TRNSYS which can be seen in Figure 4. For a constant flow of $220 \mathrm{~kg} / \mathrm{h}$ of $\mathrm{HTF}$ at $320^{\circ} \mathrm{C}$ is required a cold HTF storage tank of $6 \mathrm{~m}^{3}$ and a hot HTF storage tank of $4 \mathrm{~m}^{3}$. Due to the intermittency of the solar resource, different 
TABLE 2: Operating conditions and mass compositions of simulation streams.

\begin{tabular}{|c|c|c|c|c|c|c|}
\hline Stream & WVO & Methanol & 6 & B-diesel & MET-REC & 11 \\
\hline Mass flow (kg/h) & 100 & 39.59 & 139.5 & 109.64 & 17.09 & 12.86 \\
\hline $\mathrm{T}\left({ }^{\circ} \mathrm{C}\right)$ & 25 & 25 & 350 & 95 & 75.5 & 178.4 \\
\hline P (bar) & 1.01 & 1.01 & 100 & 1.01 & 1.01 & 1.01 \\
\hline Triolein & 0.72 & 0 & 0.010 & 0.000 & 0.000 & 0.112 \\
\hline Trilinolein & 0.18 & 0 & 0.003 & 0.000 & 0.001 & 0.027 \\
\hline Methanol & 0 & 1 & 0.138 & 0.017 & 0.987 & 0.042 \\
\hline Oleic acid & 0.06 & 0 & 0.001 & 0.001 & 0.000 & 0.000 \\
\hline Linoleic acid & 0.03 & 0 & 0.000 & 0.001 & 0.000 & 0.000 \\
\hline Linolenic acid & 0.01 & 0 & 0.000 & 0.000 & 0.000 & 0.000 \\
\hline M-oleate & 0 & 0 & 0.552 & 0.703 & 0.000 & 0.000 \\
\hline M-linoleate & 0 & 0 & 0.149 & 0.190 & 0.000 & 0.000 \\
\hline M-linolenate & 0 & 0 & 0.007 & 0.009 & 0.000 & 0.000 \\
\hline G-M-E & 0 & 0 & 0.096 & 0.076 & 0.000 & 0.396 \\
\hline $\mathrm{H}_{2} \mathrm{O}$ & 0 & 0 & 0.043 & 0.003 & 0.012 & 0.423 \\
\hline
\end{tabular}

TABLE 3: Energy demand of the biodiesel production process under supercritical conditions.

\begin{tabular}{lc}
\hline Component & Power (kW) \\
\hline Pump (B1) & 6.935 \\
Pump (B2) & 0.928 \\
Heat exchanger (B3) & 30.037 \\
Column (B8) & 13.502 \\
Total & 51.402 \\
\hline
\end{tabular}

outflows for tank 1 and tank 2 were considered, $660 \mathrm{~kg} / \mathrm{h}$ and $220 \mathrm{~kg} / \mathrm{h}$, respectively. In this way, the HTF necessary for the continuous operation of the biodiesel process is brought to the appropriate temperature for approximately $8 \mathrm{~h}$.

For the determination of the array of collectors adequate to meet the needs of the process, a group of arrangements of solar collectors was compared according to the annual solar fraction of the solar thermal storage system. Figure 5 reveals the annual solar fraction contributed by different arrays in series and parallel.

From the analysis of solar fraction, it can be observed that the use of solar energy increases as the number of collectors in series and parallel increases. Figure 5 displays the effect on the solar fraction for each proposed arrangement, where each line represents the number of collectors in series arranged by collectors in parallel according to the horizontal axis. The annual solar fraction used by different arrangements studied ranges from 0.81 to 0.82 .

Also, it can be observed that the variation in the solar fraction is considerably reduced from 13 collectors in parallel and 6 in series. As a result of the study of the thermal energy storage system for the biodiesel SCP, the collector arrangement was obtained and is presented in Table 4.

Due to thermal energy losses in tank 2, activation of the auxiliary heating system is required. Figure 6 illustrates the energy savings provided by the solar thermal storage system to the biodiesel production process, as well as the energy consumed by the same system. The energy saving is given by the energy obtained from the solar collectors. And the energy consumed by the system consists of the auxiliary heating required and the energy consumed by the system pumps.

The proposed collector array coupled with the SCP biodiesel reduces the energy consumption produced by the burning of fossil fuels.

Figure 7 displays the monthly solar fraction provided by the array of solar collectors.

It can be observed that the most significant contribution of solar energy to the process occurs in the months that comprise from March to September, where there is an input of solar energy superior to $69.5 \%$ of the thermal energy required by the biodiesel process, with a peak supply of $69.7 \%$ in June.

Figure 8 displays the different energy inputs to the biodiesel production process annually, where the $69.49 \%$ of the energy required for the process is supplied by the array of solar collectors.

3.1. Economic Analysis. An economic analysis of the biodiesel production process in supercritical condition, considering the use of solar collectors for the energy supply, was performed.

The economic analysis consisted the building of the biodiesel production process and the solar power storage system, with the specifications obtained through the performed simulations. For the analysis, the installation, operation, and maintenance costs of the process were considered, as well as the income and outcome.

The economic study was carried out in a ten-year period of operation, in which an annual average inflation of $5.5 \%$ and a recovery value of zero at the end of ten years were considered. The economic feasibility of the biodiesel production processes was compared considering the internal rate of return (IRR) of the investment, the number of periods in which the investment is paid, and the net present value of the project. 


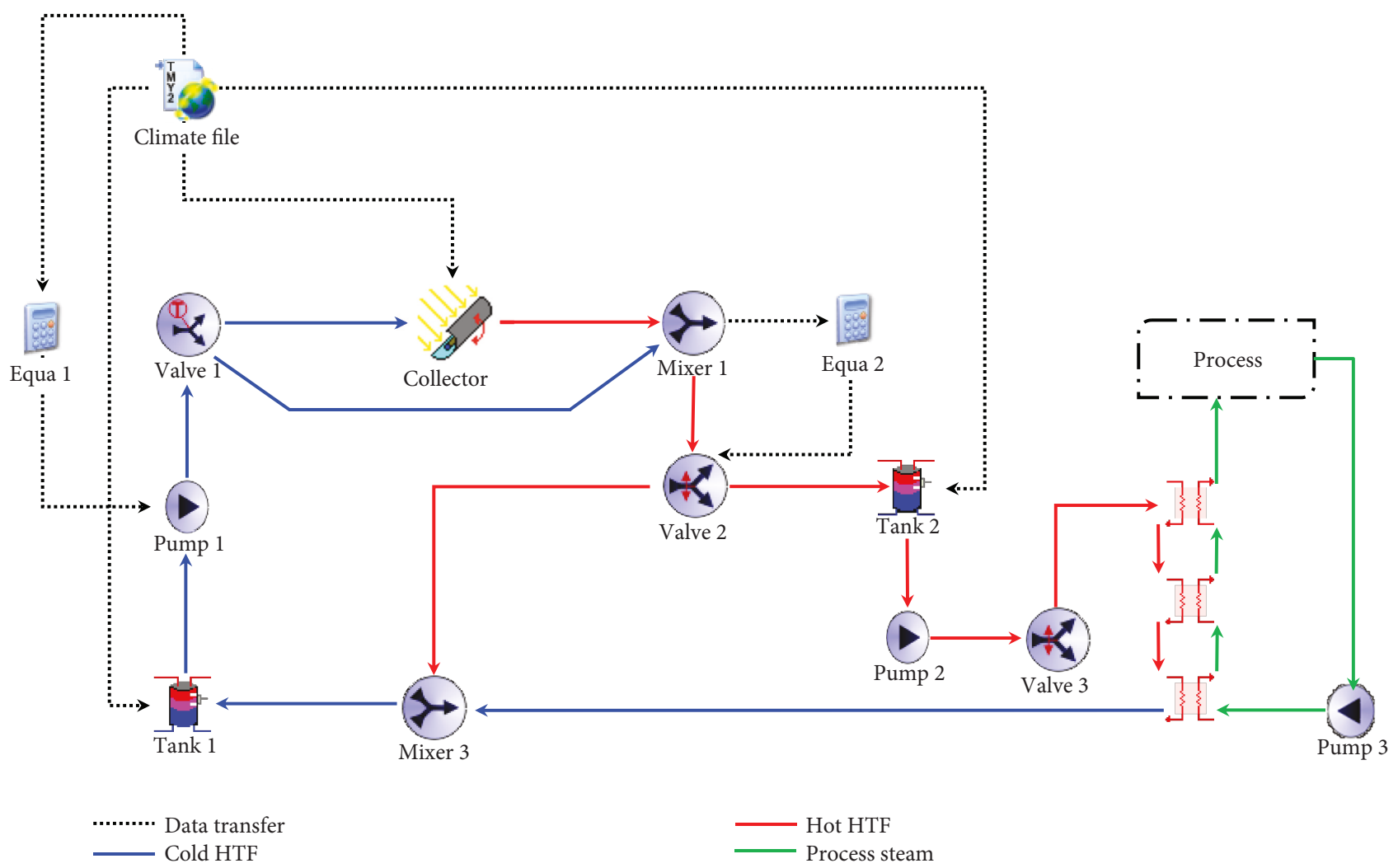

FIGURE 4: Simulation diagram in TRNSYS of the solar thermal energy storage system.

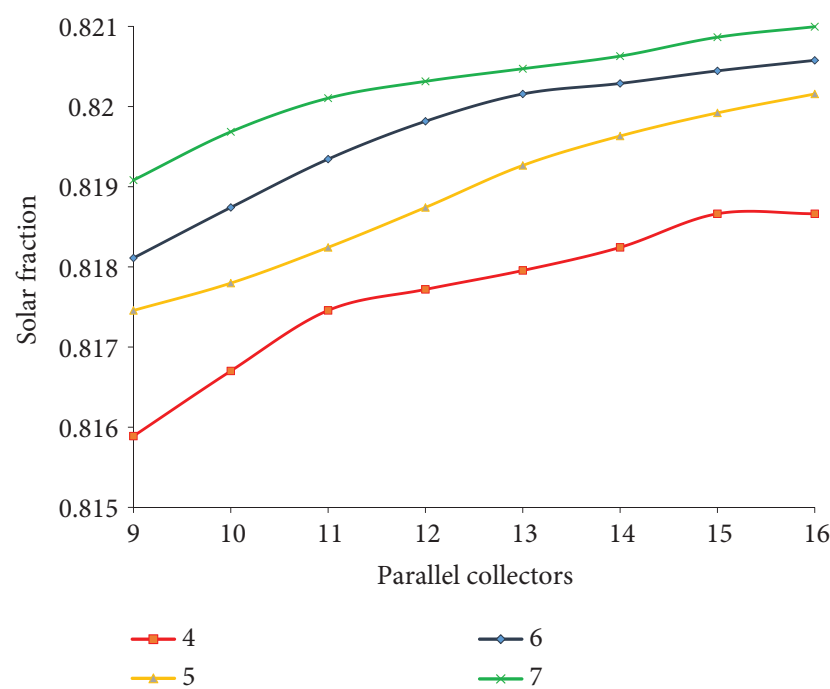

FIGURE 5: Comparison of solar collector arrangements.

In Table 5, the quantities and unit costs of the raw materials are described, as well as the required energy and its unit cost for the industrial sector of low voltage in Mexicali, Baja California.

The characteristics of the process in supercritical conditions do not require raw materials as catalysts or water for the biodiesel washing.

The required energy for biodiesel production in supercritical conditions is considerably higher than other
TABLE 4: Parameters of the array of parabolic trough collectors.

\begin{tabular}{lc}
\hline Arrangement of PTC & \\
\hline Collectors in series & 6 \\
Collectors in parallel & 13 \\
Individual collection area & $10 \mathrm{~m}^{2}$ \\
Total collection area & $780 \mathrm{~m}^{2}$ \\
Azimuth orientation & $0^{\circ}$ \\
Tilt & Solar tracking on a single axis
\end{tabular}

processes. However, it must be taken into consideration that the required energy is considered as auxiliary power because the main energy source is thermal energy, which comes from the solar system.

Table 6 presents the required equipment for the process and its estimated costs. Due to the simplicity of the process, it does not require an esterification reactor, decanter, or neutralizer, for the absence of catalysts makes more straightforward purification of biodiesel. However, for the reaction conditions, a more sophisticated and expensive transesterification reactor is required. The high energy consumption to maintain the operation process conditions in supercritical conditions requires an extensive collector's array that represents an important part of the initial investment of the project. The total cost of the investment and the operation cost are listed in Table 7.

According to the working capital, which represents the expenditures needed for the operation of the plant, and the 


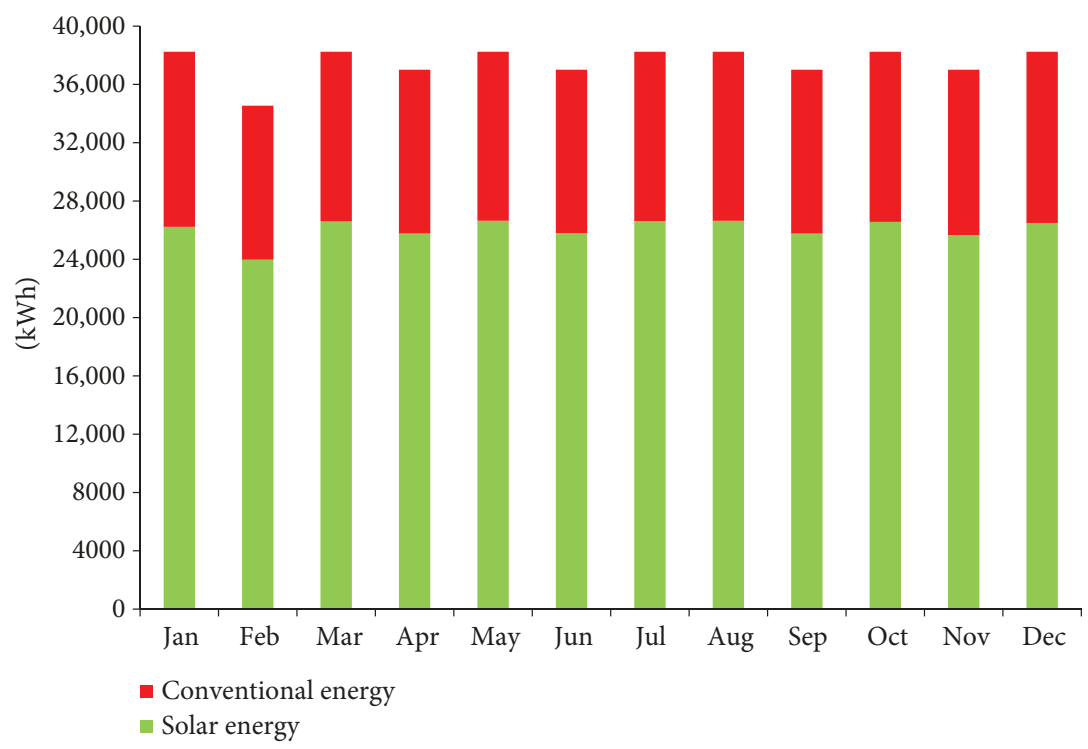

FIGURE 6: Saving and monthly energy consumption of the solar thermal energy storage system.

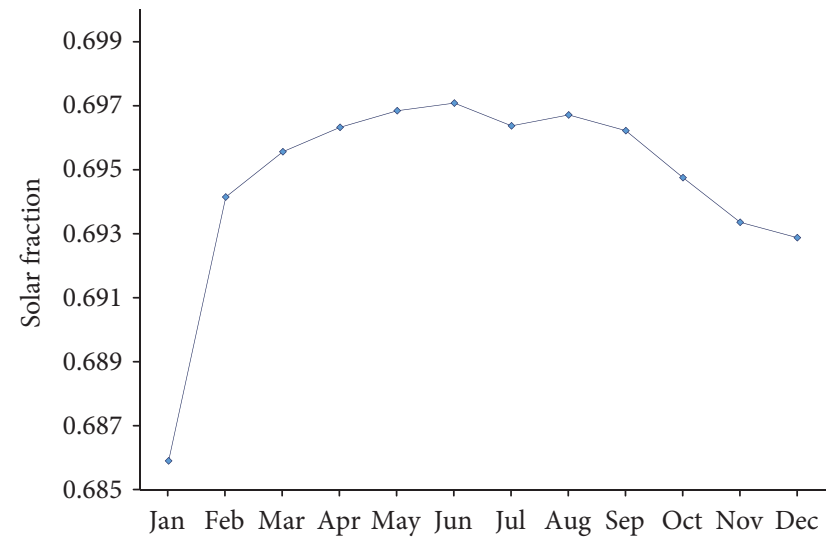

Figure 7: Monthly solar fraction of the solar thermal energy storage system.

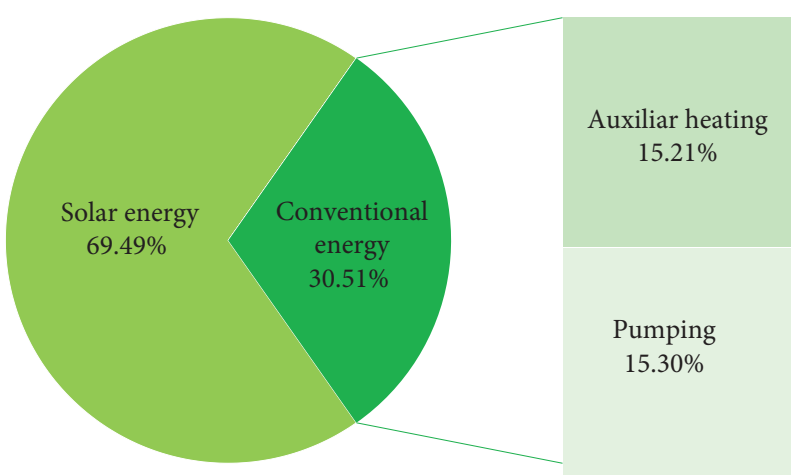

Figure 8: Annual energy contributions to the biodiesel production process at supercritical conditions.

production volume established by the performed simulations, it is possible to determine the monthly production cost and the production cost by a biofuel liter. Table 8 displays a
TABle 5: Operation costs for a month.

\begin{tabular}{lcc}
\hline Raw material & $t$ & Unit cost (USD/t) \\
Methanol & 21.28 & 540.5 \\
WVO & 53.76 & 265.67 \\
Water process & 7.91 & 25.46 \\
HTF & 3.2 & 86.04 \\
\hline Auxiliary power & MWh & USD/MWh \\
Electricity & 5.92 & 81 \\
& Total & $\mathbf{9 9 8 . 6 7}$ \\
\hline
\end{tabular}

TABLE 6: Cost of the required equipment for process.

\begin{tabular}{lc}
\hline Equipment & Thousand of USD \\
\hline Transesterification reactor & 243.24 \\
Flash separator & 54.05 \\
Distillation column & 108.11 \\
Tanks & 7.62 \\
Pumps & 44.61 \\
Heat exchangers & 24.43 \\
Solar collectors & 421.62 \\
Total & 903.68 \\
\hline
\end{tabular}

comparison of the production costs for the proposed process and other similar processes mentioned in the literature. It also indicates the trade prices of biodiesel and diesel in Mexico and the USA.

The production costs of the proposed process exceed some of the similar processes found in the literature. However, the determined location for the project allows the production cost to be competitive if compared with other current prices of fossil fuels in the north of Mexico and the USA border with Mexico, which permits offering a competitive price in the market. 
TABLE 7: Estimated investment and operation cost.

\begin{tabular}{lc}
\hline & Thousand of USD \\
\hline Direct costs & \\
Including & 932.28 \\
$\quad$ Civil work & \\
$\quad$ Machinery and equipment & \\
Indirect costs & \\
Including & 394.20 \\
$\quad$ Licenses and official permits & \\
Total investment & $\mathbf{1 3 2 6 . 4 8}$ \\
\hline Operation cost & \\
Including & \\
$\quad$ Consumables & \\
$\quad$ Leasing services & \\
$\quad$ Maintenance & \\
$\quad$ Salary &
\end{tabular}

TABLE 8: Comparison of production costs and the biodiesel trade prices (USD/l).

\begin{tabular}{ccccc}
\hline & $\begin{array}{c}\text { Proposed } \\
\text { process }\end{array}$ & {$[24]$} & {$[25]$} & {$[5]$} \\
Costs & 0.778 & 0.7525 & 0.507 & 0.623 \\
\hline \multirow{4}{*}{ Prices } & Biodiesel, & Biodiesel, & Diesel, & Diesel, \\
& MX & USA [26] & MX [27] & USA [28] \\
\hline
\end{tabular}

For the economic analysis in the ten-year period, it was considered an interbank interest annual average rate of $6.5 \%$. The economic analysis revealed that the process has an annual IRR of $31.7 \%$ which allows an investment recovery before the fifth year of operation and a positive NPV of USD $1,643,955$. It demonstrates that the proposed process would have economic and environmental benefits.

\section{Conclusions}

The production processes of biodiesel are highly benefited by the use of WVO as a raw material, due to its low cost compared to new oils, impacting the final cost of production. The biodiesel production processes in supercritical conditions have become an option of high relevance since they operate without the need of catalysts. The formation of soaps is avoided in the SCP when the amount of FFA is high and facilitates the processes of purification of biodiesel. Also, due to the lack of catalyst, the waste stream generation is diminished. The simulation in Aspen Plus allowed evaluating the energy demand of the biodiesel SCP. With this information, a solar energy capture system was modelled in TRNSYS, which allowed to supply as much energy as possible to the process. By using an array of parabolic trough collectors for the energy supply to the biodiesel production process, the burning of fossil fuels is reduced, increasing the sustainability of the process. The proposed arrangement, six collectors in series and 13 in parallel with a single collection area of $10 \mathrm{~m}^{2}$, can provide $82 \%$ of the energy required by the exchanger (B3) and the reboiler of the column (B6), which represents the $69.45 \%$ of the energy needed for the entire process annually. The estimated production cost for the proposed process is of USD $0.778 / 1$ and represents a competitive cost for a plant located on the border with the USA and the current prices of fossil fuels. The recovery of the investment takes place before finishing the fifth year, with an IRR of $31.7 \%$ and obtaining a positive NPV of USD 1,643,955. The integration and implementation of clean technologies are significant for the development and growth of biofuels and sustainable development.

\section{Data Availability}

This article is based on the integration of the results obtained from the simulations developed in the Aspen Plus and TRNSYS software. The Aspen Plus license agreement signed by the Universidad Autónoma de Baja California states that "The customer will not transfer all or part of the results of the use of the software". For this reason, access to the data is restricted.

\section{Conflicts of Interest}

The authors declare that there is no conflict of interests regarding the publication of this paper.

\section{Acknowledgments}

The authors thank the Engineering Institute of the Universidad Autónoma de Baja California for the facilities to develop this project and PFCE-2017 for the financial support for the publication of this paper.

\section{References}

[1] G. Montero, M. Stoytcheva, M. Coronado et al., "An overview of biodiesel production in Mexico," in Biofuels-Status and Perspective, K. Biernat, Ed., InTech, Rijeka, Croatia, 2015, chapter 19.

[2] A. Talebian-Kiakalaieh, N. A. Saidina Amin, and H. Mazaheri, "A review on novel processes of biodiesel production from waste cooking oil," Applied Energy, vol. 104, pp. 683-710, 2013.

[3] H. Yun, M. Wang, W. Feng, and T. Tan, "Process simulation and energy optimization of the enzyme-catalyzed biodiesel production," Energy, vol. 54, pp. 84-96, 2013.

[4] F. Gomez, V. Rico, J. G. Segovia, S. Hernandez, and M. M. El-Halwagi, "Simulation study on biodiesel production by reactive distillation with methanol at high pressure and temperature: impact on costs and pollutant emissions," Computers \& Chemical Engineering, vol. 52, pp. 204-215, 2013.

[5] S. Lee, D. Posarac, and N. Ellis, "Process simulation and economic analysis of biodiesel production processes using fresh and waste vegetable oil and supercritical methanol," Chemical Engineering Research and Design, vol. 89, no. 12, pp. 2626-2642, 2011. 
[6] K. Soteris, "Solar thermal collectors and applications," Progress in Energy and Combustion Science, vol. 30, no. 3, pp. 231-295, 2004.

[7] O. O. Odia, "Evaluation of a solar energy powered continuous absorption air-conditioning system," Indian Journal of Computer Science Theory and Practical, vol. 1, pp. 37-46, 2013.

[8] H. Müller, S. Brandmayr, and W. Zörner, "Development of an evaluation methodology for the potential of solar-thermal energy use in the food industry," Energy Procedia, vol. 48, pp. 1194-1201, 2014.

[9] J. A. León, G. Montero, M. Coronado et al., "Solar energy for a solvent recovery stage in a biodiesel production process," International Journal of Photoenergy, vol. 2016, Article ID 1048095, 7 pages, 2016.

[10] P. Lisboa, A. Rodrigues, J. Martín, P. Simões, S. Barreiros, and A. Paiva, "Economic analysis of a plant for biodiesel production from waste cooking oil via enzymatic transesterification using supercritical carbon dioxide," The Journal of Supercritical Fluids, vol. 85, pp. 31-40, 2014.

[11] L. Simasatitkul, R. Gani, and A. Arpornwichanop, "Optimal design of biodiesel production process from waste cooking palm oil," Procedia Engineering, vol. 42, pp. 1292-1301, 2012.

[12] A. Mohammadshirazi, A. Akram, S. Rafiee, and E. Bagheri Kalhor, "Energy and cost analyses of biodiesel production from waste cooking oil," Renewable and Sustainable Energy Reviews, vol. 33, pp. 44-49, 2014.

[13] B. Jowett and A. Dansby, "Aceite de canola: saludable, versátil y de la mejor calidad," Asociación Nacional de Industriales de Aceites y Mantecas Comestibles, vol. 17, pp. 16-19, 2014.

[14] R. Przybylski, Canola Oil Physical and Chemical Properties, Canola Council of Canada, 2011, http://www.canolacouncil.org.

[15] V. Marulanda, "Biodiesel production by supercritical methanol transesterification: process simulation and potential environmental impact assessment," Journal of Cleaner Production, vol. 33, pp. 109-116, 2012.

[16] S. Kuravi, J. Trahan, D. Yogi, M. Rahman, and E. Stefanakos, "Thermal energy storage technologies and systems for concentrating solar power plants," Progress in Energy and Combustion Science, vol. 39, no. 4, pp. 285-319, 2013.

[17] V. López, "La energía solar como promotora del desarrollo regional: análisis del potencial de generación en Baja California," Revista internacional administración \& finanzas, vol. 5, pp. 53-64, 2012.

[18] M. Eck and K. Hennecke, "Heat transfer fluids for future parabolic trough solar thermal power plants," in Proceedings of ISES World Congress 2007 (Vol. I - Vol. V), D. Y. Goswami and Y. Zhao, Eds., pp. 1806-1812, Springer, Berlin, Heidelberg, 2008.

[19] X. Zhang, W. Xu, T. He et al., "Solar thermal system evaluation in China," International Journal of Photoenergy, vol. 2015, Article ID 163808, 12 pages, 2015.

[20] S. Kalogirou, "Use of TRNSYS for modelling and simulation of a hybrid pv-thermal solar system for Cyprus," Renewable Energy, vol. 23, no. 2, pp. 247-260, 2001.

[21] A. Hobbi and K. Siddiqui, "Optimal design of a forced circulation solar water heating system for a residential unit in cold climate using TRNSYS," Solar Energy, vol. 83, no. 5, pp. 700-714, 2009.

[22] J. A. Duffie and W. A. Beckman, Solar Engineering of Thermal Processes, Wiley, New York, NY, USA, 1991.
[23] The German Solar Society, Planning and Installing Solar Thermal Systems - A Guide for Installers, Architects and Engineers, Earthscan, 2005, https://www.crcpress.com/ Planning-and-Installing-Solar-Thermal-Systems-A-Guide-forInstallers-Architects/Dgs/p/book/9781844071258.

[24] J. F. O. Granjo, B. P. M. Duarte, and N. M. C. Oliveira, "Integrated production of biodiesel in a soybean biorefinery: modeling, simulation and economical assessment," Energy, vol. 129, pp. 273-291, 2017.

[25] F. J. Gutiérrez Orti and P. de Santa-Ana, “Techno-economic assessment of an energy self-sufficient process to produce biodiesel under supercritical conditions," The Journal of Supercritical Fluids, vol. 128, pp. 349-358, 2017.

[26] Office of Energy Efficiency \& Renewable Energy, “Alternative fuels data center," 2017, March 2018, http://www.afdc.energy. gov/fuels/prices.html.

[27] Comisión Reguladora de Energía, "Precios de gasolinas y diésel," March 2018, http://www.cre.gob.mx/ConsultaPrecios/ GasolinasyDiesel/GasolinasyDiesel.html.

[28] US Energy Information Administration, "Monthly retail gasoline and diesel prices for California," 2018, March 2018, https://www.eia.gov/. 

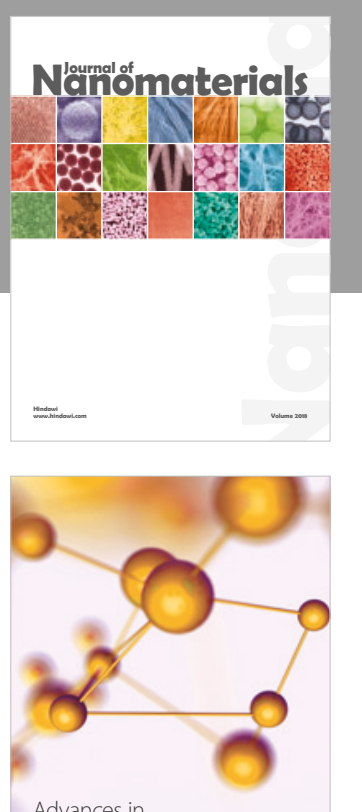

Physical Chemistry
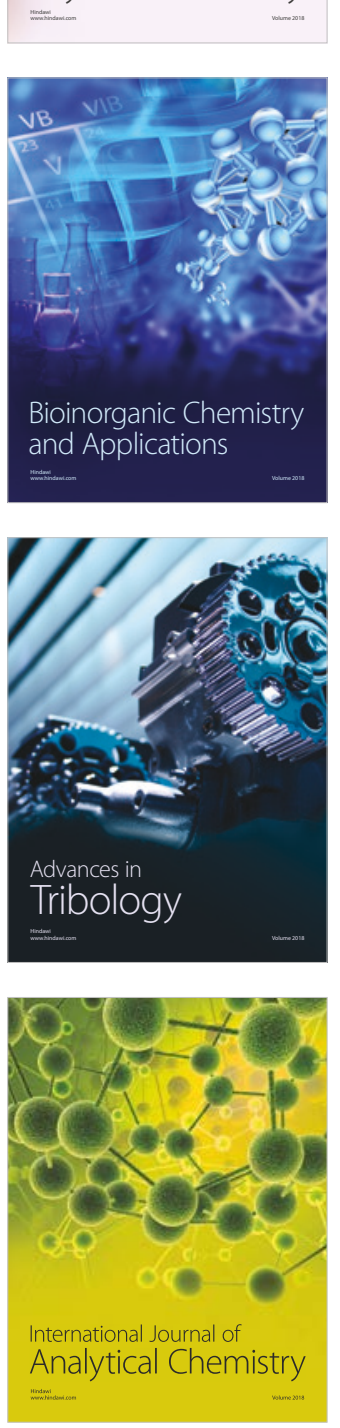

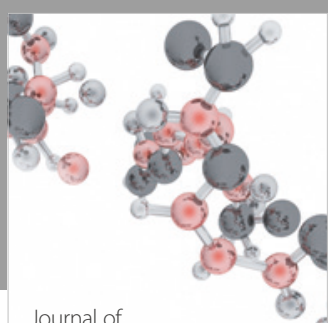

Analytical Methods

in Chemistry

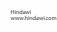

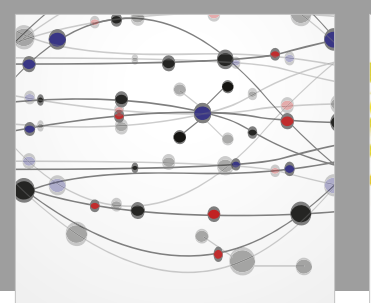

The Scientific World Journal

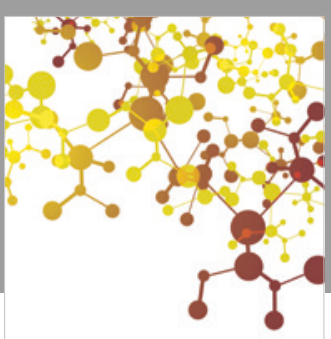

Journal of

Applied Chemistry
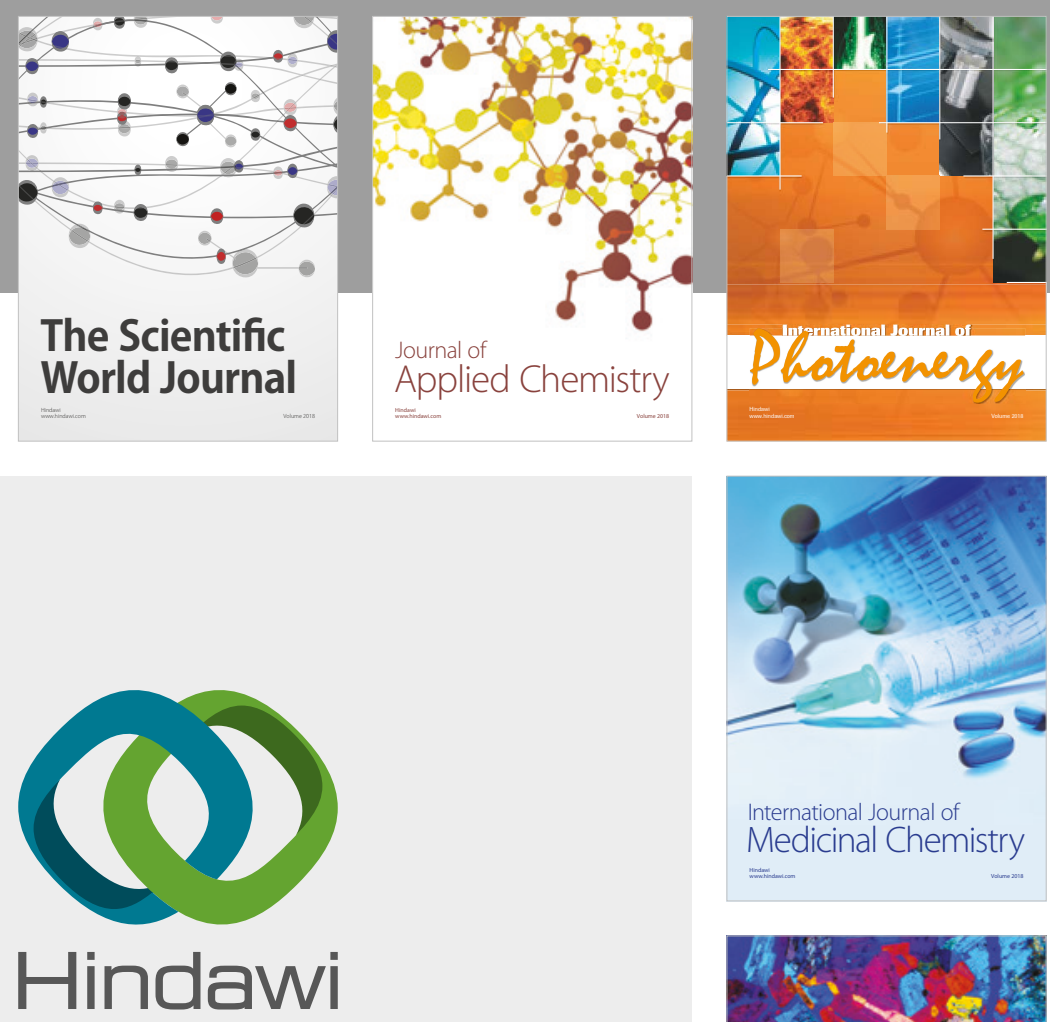

Submit your manuscripts at

www.hindawi.com
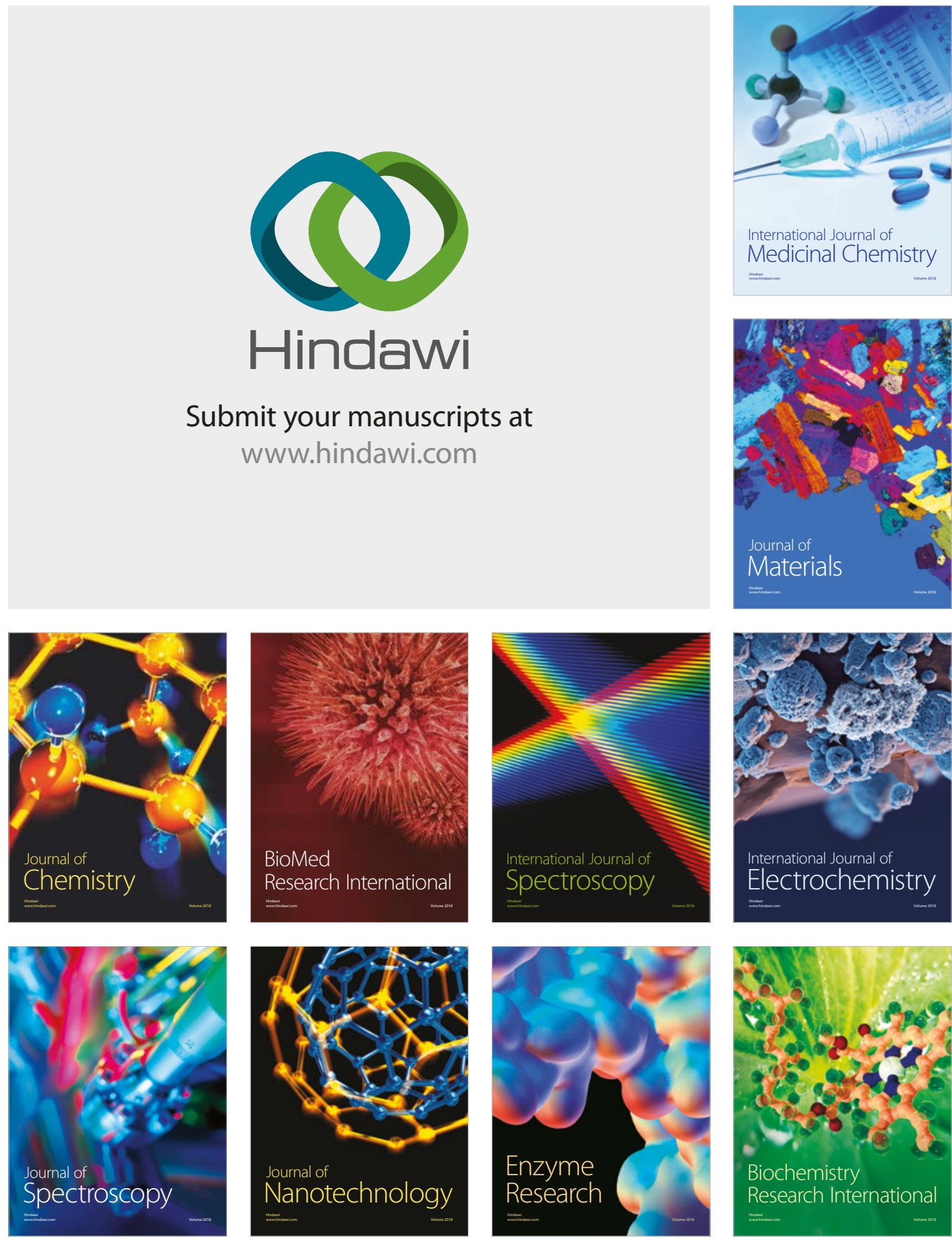
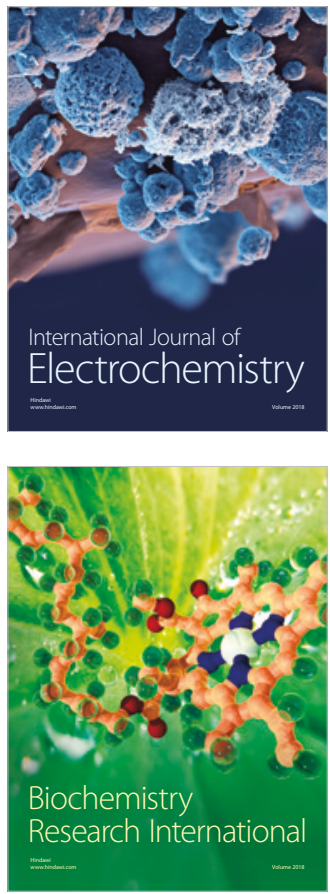